\title{
Gender gap in health expectancy
}

\author{
Anna Oksuzyan • Henrik Brønnum-Hansen • \\ Bernard Jeune
}

Published online: 4 November 2010

(C) Springer-Verlag 2010

\begin{abstract}
Men have higher death rates than women, but women do worse with regard to physical strength, disability, and other health outcomes, the so called malefemale health-survival paradox. The paradox is likely to be due to multiple causes that include biological, behavioral, and social differences between the sexes. Despite decades of research on the male-female health-survival paradox, we still do not fully recognize whether behavioral factors explain most of the gender gap or whether biological and social differences contribute more substantially to the explanation of the sex differences in health and mortality. Little work has been done to investigate the magnitude of sex differences in healthy life expectancy and unhealthy life expectancy, as well as to examine the contribution of mortality and disability levels to the sex gap in health expectancy. The five selected works presented at the Réseau Espérance de Vie en Santé (REVES) Meeting 2009 in Copenhagen, and published in this issue, provide new insights into sex differences in health expectancy. The papers examine sex differences in health expectancy indicators in the EU countries, as well as trends in health
\end{abstract}

Communicated by Dorly J.H. Deeg.

A. Oksuzyan $(\bowtie) \cdot$ B. Jeune

The Danish Aging Research Center, Epidemiology,

Institute of Public Health, University of Southern Denmark,

J.B. Winsløws Vej 9B, 5000 Odense, Denmark

e-mail: aoksuzyan@health.sdu.dk

\section{A. Oksuzyan}

Max Planck Institute for Demographic Research, Rostock, Germany

H. Brønnum-Hansen

National Institute of Public Health, University of Southern

Denmark, Øster Farimagsgade 5 A, 1353 Copenhagen, Denmark expectancy in Hong Kong and in the US. They go beyond description of sex differences in health expectancy and assess the contributions of mortality and disability to gender differences in healthy life years and unhealthy life years, investigate temporal changes in sex differential health expectancy, as well as analyze contributions of time and age dimensions to the gender gap. They also show that there is still work to be done to indentify and quantify mechanisms underlying sex differences in longevity, health, and aging.

Men die, women suffer: that is what is called the malefemale health paradox (Nathanson 1975; Wingard 1984; Waldron 1995; Case and Paxson 2005; Barford et al. 2006; Oksuzyan et al. 2008). At all ages male death rates are higher than that of females indicating that in terms of mortality women are healthier than men. However, women do worse with regard to disability and other health outcomes (Jagger et al. 2008; Schön and Parker 2008; Christensen et al. 2009; Crimmins et al. 2010). What are recent developments of sex differences in mortality, life expectancy, and health expectancy? Is the gender gap after several decades of increasing trends now decreasing? What are the reasons for these changes?

In 1955 Jeff N. Morris showed that in the second half of the nineteenth century in United Kingdom (UK), the death rates were high and increasing among middle-aged individuals (Morris 1955). Men had only about 10\% higher death rates than their same-aged female counterparts. Thereafter, due to improved living conditions death rates began to fall from 1900 and continued to decline until the 1920s. From the 1920s, trends in mortality diverged by sexes: improvements in mortality rates stagnated among men, whereas they continued to decline among women. In 
the 1950s, a middle-aged man had almost twice higher death rates compared with the same-aged woman. Morris showed that all-cause mortality among men continued to fall from 1920 to 1950 when coronary heart disease and cancer of respiratory system were excluded, suggesting that the increasing sex differential mortality in UK was primarily due to the beginning of a modern epidemic of coronary heart disease and lung cancer related to increasing smoking behavior among men (Morris 1955).

Previous research on trends of the sex differential in mortality showed that within the first three quarters of the twentieth century the gender gap widened in most industrialized countries (Nathanson 1975; Waldron 1985; Rigby and Dorling 2007). Since the 1970s, sex differences in life expectancy start declining in most developed countries, although the timing of the narrowing of the sex differential in mortality varied across these countries (Gjonca et al. 2005; Glei and Horiuchi 2007). Only in Japan the sex differential in life expectancy continues to widen due to relatively small improvements in mortality from circulatory diseases and increasing mortality from cancer and external causes among men.

Despite consistently higher survival rates at all ages among women than among men, the female advantage seems to be less pronounced when health is measured as lifetime in a healthy state (Jagger et al. 2008). Health expectancy indicators are important and useful to assess population health as they represent a refinement of life expectancy by combining quantitative and qualitative information about the total length of life and length of life spent in different health states (Sullivan 1971). Since they can be based on various concepts of health, it is possible to estimate several health expectancy indicators (Robine 2002; Robine et al. 2003). Previous studies showed that different trends were observed for different health expectancy measures, populations, and time periods under investigation (Robine 2006; Cambois et al. 2008; Jeune and Brønnum-Hansen 2008; Parker et al. 2008).

Recent review articles illustrate that although old-aged mortality has been substantially postponed in most industrialized countries, research evidence on trends in health expectancies, chronic diseases, and disability rates at very old ages is inconsistent (Christensen et al. 2009; Vaupel 2010). Little work has been done to investigate the magnitude of sex differences in healthy life expectancy and unhealthy life expectancy, as well as to examine the contribution of mortality and disability levels to the sex gap in health expectancy.

The Réseau Espérance de Vie en Santé (REVES) is an international organization that promotes the use of health expectancy as a population health indicator and is involved in the definition and measurement of disability globally to facilitate cross-country comparison studies (REVES
1989-2010). The annual REVES meeting in 2009 in Copenhagen was held to study and quantify differences in health expectancy between men and women as well as inequalities between socioeconomic groups and subpopulations of different ethnicity.

The following issue is based on five selected works presented at the 2009 REVES Meeting. Three studies focused on sex differences in health expectancy indicators in the EU countries (Frova et al. 2010; Nusselder et al. 2010; Van Oyen et al. 2010) and two studies examined trends in health expectancy in Hong Kong and in the US (Cheung and Yip 2010; Reynolds and Crimmins 2010).

Based on the European Union Statistics on Income and Living Conditions Survey (EU-SILC) Nusselder et al. and Van Oyen et al. showed that patterns of sex differences in healthy life expectancy and unhealthy life expectancy are divergent in the original EU15 and the new EU10 states (2010). Remarkably, life expectancies with and without activity limitations at age 50 were found to be higher among women than among same-aged men in all EU countries, except in Cyprus, Portugal, and Spain, where life expectancy in good health was greater among men than among women (Van Oyen et al. 2010). The sex difference in life expectancy with and without activity limitations was generally larger in the EU10 than in the EU15 countries (Nusselder et al. 2010). Decomposition analysis by Nusselder et al. revealed that the absence of the gender difference in Healthy Life Years at age 15 in the original EU states was due to almost complete compensation of the female advantage in survival by higher disability levels. Similar magnitudes of sex differences in Unhealthy Life Years in the EU10 and the EU15 countries masked important disadvantage among the EU10 men: stronger mortality disadvantage at younger ages and small or virtually absent disability advantage than in the EU15 men (Nusselder et al. 2010).

Van Oyen and colleagues showed that the gender gap in life expectancy with activity limitations at age 50 in the original and new EU countries was negatively associated with gross domestic product, expenditures on elder care and life-long learning (2010). Despite the cross-sectional nature of these studies and, thus, inability to examine causal associations, they have important implications for the future suggesting that the sex differences in health expectancy indicators are amendable to reduction via improved elder care and reduced income inequality.

Nusselder et al. and Van Oyen et al. emphasized difficulties of international comparison studies even when substantial efforts have been done to harmonize data collection instruments in the SILC (2010). Some cross-country differences can be explained by methodological differences in data collection instruments, mode of data collection, and patterns of non-response (Ekholm and Brønnum-Hansen 
2009), although within-country comparison of sex differences in health expectancy is less sensitive to such issues. It should also be mentioned that different patterns of sex differences in health expectancy could have emerged if the authors had longitudinal data and/or included institutionalized individuals. Cambois et al. (2008) showed that for France the size of the error when considering all years lived in institutions as years of disability is negligible for life expectancy without functional limitations at age 65 and very small for life expectancy without personal care activity restriction. However, the proportion of institutionalized individuals, criteria for and sex-specific patterns of institutionalization may vary across countries.

The other three papers presented in this issue examined the trends of sex differences in health expectancy indicators. Frova et al. showed that the sex differences in total and disability free life expectancy at age 30 decreased from 1994 to 2005 in Italy (2010). These trends were explained by a combination of increasing disability trends among women and more rapid decreases in male mortality in this period. The largest contribution due to disability was observed among women aged 85 years and older and due to mortality among 55-84-year-old men.

US data showed that health at older ages, defined as work ability, improved modestly from 1997 to 2007, similar in men and women (Reynolds and Crimmins 2010). These trends were largely explained by increased averaged educational level over the period and would have been greater without increased obesity over this period. This study highlights that future trends in work ability at older ages may be unclear considering increasing trends in obesity in the US and other developed countries (Wang and Lobstein 2006). In contrast, in Hong Kong, an increase in total life expectancy from 1996 to 2008 was accompanied with longer life with chronic morbidity and disability and this health deterioration was found to be greater among women than among men (Cheung and Yip 2010). Cheung and Yip suggest that changes in question wording and interval between consecutive waves may influence the estimates of morbidity and disability prevalence and, thus, the observed trends should be interpreted cautiously.

Previous research reports that women report worse selfrated health than men, although the magnitude of sex differences varies across EU countries (Bambra et al. 2008). It has also been demonstrated that men have superior physical performance (Jeune et al. 2006; Oksuzyan et al. 2010) and fewer limitations in functional abilities compared with the same-aged women (Crimmins et al. 2010). However, the literature on the female disadvantage in morbidity is less consistent and depends on the selected measure of illness, definition of the disease, and its age-related trajectories, as well as the period under investigation. Previous studies have indicated that men report having more life-threatening conditions, whereas women tend to have more non-life-threatening conditions (Case and Paxson 2005). Case and Paxson showed that sex differences in self-reported health were fully explained by sex differences in the distribution of chronic diseases. In 11 European countries and the USA, arthritis and depression were more common among women, whereas men were more likely to suffer from heart diseases (Crimmins et al. 2010). A study among very old Swedes revealed no significant sex differences in rates of depression in 1992, but women had higher depression rates than men in 2002 (Schön and Parker 2008). Although men have substantially higher risks of coronary heart disease (CHD) before age 60, the male excess of $\mathrm{CHD}$ incidence declines considerably after age 60 (Rich-Edwards et al. 1995).

A number of mechanisms have been proposed to explain the male-female health-survival paradox. Gender differences in biological risks, and risks acquired through social roles, lifestyle, and health behaviors were suggested as the most common explanations for sex differences in health and mortality (Nathanson 1975; Wingard 1984; Waldron 1985; Verbrugge and Wingard 1987; Verbrugge 1989; Case and Paxson 2005). The most prominent biological explanations for the differences in male and female health and mortality are hormonal [favorable effects of estrogen on serum lipids and prevention of degenerative processes via its protective effect on brain cells (Waldron 1995; McEwen and Alves 1999)], autoimmune (greater susceptibility of men to infections) (Crimmins and Finch 2006), and genetic (the lack of a second $\mathrm{X}$ chromosome in men) (Christensen et al. 2000; Austad 2006; Morris and Harrison 2009).

It has been consistently demonstrated that men engage more frequently in risky behaviors, such as the use of tobacco, alcohol, and psychoactive substance, less safe driving, and less healthy eating, resulting in elevated risks of CHD, lung cancer, chronic obstructive pulmonary diseases, liver cirrhosis, and accident fatalities (Waldron 1985; Wardle et al. 2004). Cigarette smoking has been identified as the single largest factor for explanation of sex differential mortality in high-income countries (Jacobsen et al. 2008; Katanoda et al. 2008; Preston et al. 2009). Preston et al. (2009) showed that although smokingattributable fraction of deaths was much higher among men than women across all developed countries, it rapidly increased among women from 1955 to 2003, whereas the patterns were divergent among men. The impact of highly prevalent lifestyle-related risk factors on health expectancy has been studied in Denmark. Overweight, obesity, or being physical inactive reduced expected lifetime without long-standing illness much more for women than men, whereas the impact of heavy smoking did not differ between genders (Brønnum-Hansen et al. 2007). Another 
Danish study showed that the impact of smoking on life expectancy and health expectancy was present irrespective of educational level and that the social gap in expected lifetime in good health was widest among female heavy smokers and much larger than for male heavy smokers (Brønnum-Hansen and Juel 2004). Smaller sex differentials in life expectancy at birth among Israeli Jews compared to the populations in Western countries were mainly due to lower mortality among Israeli men for causes of death related to lifestyle behavior: lung and aerodigestive cancer, liver cirrhosis, and external causes (Staetsky and Hinde 2009). These findings point toward the end of the modern epidemic of CHD and lung cancer for men described by Morris (1955) and emphasize the importance of genderspecific lifestyle behavior in explaining sex differences in health and mortality. Although behavioral factors contribute substantially to the increased mortality from cardiovascular and other chronic diseases in men, they cannot fully explain sex-differences in mortality as suggested by the female advantage in life expectancy among nonsmokers (Valkonen and Van Poppel 1997).

Sex differences in risks acquired through social roles and health behaviors have also been suggested to partially explain sex differences in morbidity and mortality (Wingard 1984). Women were found to be more interested in health (Green and Pope 1999), to report more symptoms (Kroenke and Spitzer 1998) and to show higher healthcare utilization than men did (Wingard 1984). The finding that men have lower levels of primary care use, but higher hospitalization rates than women suggests that men may disregard early signs of disease and postpone going to the doctor until the later stages of disease development (Galdas et al. 2005; Juel and Christensen 2007). However, other studies found no apparent gender differences in the accuracy of reporting health problems or prescription medications (Macintyre et al. 1999; Oksuzyan et al. 2009). Additionally, in contemporary industrial societies with more fathers taking on household responsibilities and caring for children, and more women working, the contribution of the traditional distribution of gender roles in explaining sex differences in health and mortality may have diminished.

Some of the difference could be due to selection and information bias in surveys, if men are reluctant to participate and/or report health related information if they have diseases or disabilities. The Danish data showed that selection bias in surveys may contribute to the explanation of the health-survival paradox, but its contribution is likely to be small (Oksuzyan et al. 2009). Male disadvantage in mortality around periods of stress, such as spousal loss (Erlangsen et al. 2004), can be partially explained by interrupted medical treatment among men. A recent study among 65 years and older persons suggested that loss of informal care, self-care and healthcare coordination rather than formal contacts with healthcare providers may contribute to higher excess mortality in widowers compared with widows (Jin and Chrisatakis 2009).

In conclusion, the five research papers presented in the current issue of the European Journal of Ageing provide the audience with new insights into sex differences in health expectancy. They go beyond description of sex differences in health expectancy and assess the contributions of mortality and disability to gender differences in healthy life years and unhealthy life years, investigate temporal changes in sex differential health expectancy, as well as analyze contributions of time and age dimensions to the gender gap. However, there is still work to be done to indentify and quantify mechanisms underlying sex differences in longevity, health, and aging. Despite decades of research on the male-female health-survival paradox, we still do not fully recognize whether behavioral factors explain most of the gender gap or whether biological and social differences contribute more substantially to the explanation of the sex differences in health and mortality. Future studies may also aim to improve methodological problems, e.g. investigate sex differences in health expectancy across populations that include institutionalized persons. Although population aging occurs worldwide, its timing and pace may differ across genders and countries. Continuous monitoring of trends in health expectancy may help to solve the ongoing debate whether longer lives are accompanied by worse health at old ages, especially among women, and may help to meet future needs of aging societies and ensure their sustainability.

\section{References}

Austad S (2006) Why women live longer than men: sex differences in longevity. Gend Med 3(2):79-92

Bambra C, Pope DP et al (2008) Gender, health inequalities and welfare state regimes: a cross-national study of thirteen European countries. J Epidemiol Community Health 63:38-44

Barford A, Dorling D et al (2006) Life expectancy: women now on top everywhere. BMJ 332(7545):808

Brønnum-Hansen H, Juel K (2004) Impact of smoking on the social gradient in health expectancy in Denmark. J Epidemiol Community Health 58:604-610

Brønnum-Hansen H, Juel K et al (2007) Impact of selected risk factors on expected lifetime without long-standing, limiting illness in Denmark. Prev Med 45:49-53

Cambois E, Clavel A et al (2008) Trends in disability-free life expectancy at age 65 in France: consistent and diverging patterns according to the underlying disability measure. Eur J Ageing 5(4):287-298

Case A, Paxson C (2005) Sex differences in morbidity and mortality. Demography 42(2):189-214

Cheung SLK, Yip SFP (2010) Trends in healthy life expectancy in Hong Kong SAR 1996-2008. Eur J Ageing 7(4). doi:10.1007/ s10433-010-0171-3 
Christensen K, Kristiansen M et al (2000) X-linked genetic factors regulate hematopoietic stem-cell kinetics in females. Blood 95(7):2449-2451

Christensen K, Doblhammer G et al (2009) Ageing populations: the challenges ahead. Lancet 374(9696):1196-1208

Crimmins EM, Kim JK et al (2010) Gender differences in health: results from SHARE, ELSA and HRS. Eur J Public Health ckq022

Crimmins EM, Finch CE (2006) Commentary: do older men and women gain equally from improving childhood conditions? Int $\mathbf{J}$ Epidemiol 35(5):1270-1271

Ekholm O, Brønnum-Hansen H (2009) Cross-national comparisons of non-harmonized indicators may lead to more confusion than clarification. Scand J Public Health 37(6):661-663

Erlangsen A, Jeune B et al (2004) Loss of partner and suicide risks among oldest old: a population-based register study. Age Ageing 33(4):378-383

Frova L, Burgio A et al (2010) Are gaps in disability free life expectancies diminishing in Italy? Eur J Ageing 7(4). doi: 10.1007/s10433-010-0173-1

Galdas PM, Cheater F et al (2005) Men and health help-seeking behaviour: literature review. J Adv Nurs 49(6):616-623

Gjonca A, Tomassini C et al (2005) Sex differences in mortality, a comparison of the United Kingdom and other developed countries. Health Stat Q 26:6-16

Glei DA, Horiuchi S (2007) The narrowing sex differential in life expectancy in high-income populations: effects of differences in the age pattern of mortality. Popul Stud (Camb) 61(2):141-159

Green CA, Pope CR (1999) Gender, psychosocial factors and the use of medical services: a longitudinal analysis. Soc Sci Med 48(10): 1363-1372

Jacobsen R, Oksuzyan A et al (2008) Sex differential in mortality trends of old-aged Danes: a nation wide study of age, period and cohort effects. Eur J Epidemiol 23(11):723-730

Jagger C, Gillies C et al (2008) Inequalities in healthy life years in the 25 countries of the European Union in 2005: a cross-national meta-regression analysis. Lancet 372(9656):2124-2131

Jeune B, Brønnum-Hansen H (2008) Trends in health expectancy at age 65 for various health indicators, 1987-2005, Denmark. Eur J Ageing 5:279-285

Jeune B, Skytthe A et al (2006) Handgrip strength among nonagenarians and centenarians in three European regions. J Gerontol A Biol Sci Med Sci 61(7):707-712

Jin L, Chrisatakis NA (2009) Investigating the mechanism of marital mortality reduction: the transition to widowhood and quality of health care. Demography 46(3):605-625

Juel K, Christensen K (2007) Are men seeking medical advice too late? Contacts to general practitioners, hospital admissions in Denmark 2005. J Public Health 30(1):111-113

Katanoda K, Marugame T et al (2008) Population attributable fraction of mortality associated with tobacco smoking in Japan: a pooled analysis of three large-scale cohort studies. J Epidemiol 18(6):251-264

Kroenke K, Spitzer RL (1998) Gender differences in the reporting of physical and somatoform symptoms. Psychosom Med 60(2): $150-155$

Macintyre S, Ford G et al (1999) Do women 'over-report' morbidity? Men's and women's responses to structured prompting on a standard question on long standing illness. Soc Sci Med 48(1):89-98

McEwen BS, Alves SE (1999) Estrogen actions in the central nervous system. Endocr Rev 20(3):279-307

Morris JN (1955) Uses of epidemiology. BMJ 2(4936):395-401

Morris JA, Harrison LM (2009) Hypothesis: increased male mortality caused by infection is due to a decrease in heterozygous loci as a result of a single X chromosome. Med Hypotheses 72(3): $322-324$
Nathanson CA (1975) Illness and the feminine role: a theoretical review. Soc Sci Med 9(2):57-62

Nusselder W, Looman C et al (2010) Gender differences in health of EU10 and EU15 populations: the double burden of EU10 men. Eur J Ageing 7(4). doi:10.1007/s10433-010-0169-x

Oksuzyan A, Juel K et al (2008) Men: good health and high mortality. Sex differences in health and aging. Aging Clin Exp Res 20(2): 91-102

Oksuzyan A, Petersen I et al (2009) The male-female health-survival paradox: a survey and register study of the impact of sexspecific selection and information bias. Ann Epidemiol 19(7): 504-511

Oksuzyan A, Crimmins E et al (2010) Cross-national comparison of sex differences in health and mortality in Denmark, Japan and the US. Eur J Epidemiol 25(7):471-480

Parker M, Schön P et al (2005) Functional ability in the elderly Swedish population from 1980 to 2005. Eur J Ageing 5(4):299-309

Preston SH, Glei DA et al (2009) A new method for estimating smoking-attributable mortality in high-income countries. Int J Epidemiol 39:430-438

REVES. (1989-2010) REVES, the network on health expectancies and the disablement process. http://reves.site.ined.fr/en/. Accessed 27 Jul 2010

Reynolds SL, Crimmins EM (2010) Trends in the ability to work among men and women in the older American population: 1997-2007. Eur J Ageing 7(4). doi:10.1007/s10433-0100166-0

Rich-Edwards JW, Manson JE et al (1995) The primary prevention of coronary heart disease in women. N Engl J Med 332(26): $1758-1766$

Rigby JE, Dorling D (2007) Mortality in relation to sex in the affluent world. J Epidemiol Community Health 61(2):159-164

Robine J (2002) A new health expectancy classification system. In: Murray C, Salomon J, Mathers C, Lopez A (eds) Summary measures of population health. Geneva, WHO, pp 205-212

Robine JM (2006) Trends in population health. Aging Clin Exp Res 18(5):349-351

Robine J-M, Jagger C et al (2003) Creating a coherent set of indicators to monitor health across Europe: the Euro-REVES 2 project. Eur J Public Health 13(suppl_1):6-14

Schön P, Parker MG (2008) Sex differences in health in 1992 and 2002 among very old Swedes. J Popul Ageing 1(2):107-123

Staetsky L, Hinde A (2009) Unusually small sex differentials in mortality of Israeli Jews: what does the structure of causes of death tell us? Demogr Res 20(11):209-252

Sullivan DF (1971) A single index of mortality and morbidity. HSMHA Health Rep 86(4):347-354

Valkonen T, Van Poppel F (1997) The contribution of smoking to sex differences in life expectancy: four Nordic countries and The Netherlands 1970-1989. Eur J Public Health 7(3):302-310

Van Oyen H, Cox B et al (2010) Gender gaps in life expectancy and expected years with activity limitations at age 50 in the European Union: associations with macro-level structural indicators. Eur J Ageing 7(4). doi:10.1007/s10433-010-0172-2

Vaupel JW (2010) Biodemography of human ageing. Nature 464(7288):536-542

Verbrugge LM (1989) The twain meet: empirical explanations of sex differences in health and mortality. J Health Soc Behav 30(3): 282-304

Verbrugge LM, Wingard DL (1987) Sex differentials in health and mortality. Women Health 12(2):103-145

Waldron I (1985) What do we know about causes of sex differences in mortality? A review of the literature. Popul Bull UN 18: $59-76$

Waldron I (1995) Contributions of biological and behavioral factors to changing sex differences in ischemic heart disease mortality. 
In: Lopez AD, Caselli G, Valkonen T (eds) Adult mortality in developed countries: from description to explanation. Oxford University Press, Oxford

Wang Y, Lobstein $T$ (2006) Worldwide trends in childhood overweight and obesity. Int J Pediatr Obes 1(1):11-25
Wardle J, Haase AM et al (2004) Gender differences in food choice: the contribution of health beliefs and dieting. Ann Behav Med 27(2):107-116

Wingard DL (1984) The sex differential in morbidity, mortality, and lifestyle. Annu Rev Public Health 5(1):433-458 